\author{
오차드그라스 신품종 “온누리”의 생육특성과 수량성 \\ 지희정* · 이상훈 · 김기용·최기준 · 박남건 · 이기원 \\ 국립축산과학원, 천안, $330-801$
}

\title{
Growth Characteristics and Productivity of New Orchardgrass (Dactylis glomerata L.) Cultivar, "Onnuri"
}

\author{
Hee Chung. Ji*, Sang Hoon Lee, Gi Yong Kim, Gi Jun Choi, Nam Gun Park and Ki Won Lee \\ National Institute of Animal Science, Cheonan, 330-801, Korea
}

\begin{abstract}
"Onnuri" is a new orchardgrass (Dactylis glomerata L.) cultivar developed by the National Institute of Animal Science (NIAS) in 2011. To develop the new variety of orchardgrass, 5 superior clones were selected and polycrossed for seed production. The agronomic growth characteristics and forage productivity of "Onnuri" were examined at Cheonan from 2009 to 2011, and regional trials were conducted in Cheonan, Pyeongchang, Jinju and Jeju from 2009 to 2011, respectively. "Onnuri" showed medium type growth habit in fall and spring, and medium in length of flag leaf and long upper internode. Plant height of "Onnuri" was $5 \mathrm{~cm}$ more than that of the standard cultivar, "Amba" and the heading date was 5 days earlier than that of Amba (16th May). Characteristics, such as waterlogging and disease resistance, of "Onnuri" were stronger or better than those of Amba, Especially, dry matter yield of "Onnuri" (14,775 kg/ha) increased by $18 \%$ compared to that of Amba $(12,523 \mathrm{~kg} / \mathrm{ha})$. Nutritive values appeared to be similar in both varieties.
\end{abstract}

(Key words : Orchardgrass, Synthetics, Polycross, Forage crop, Variety)

\section{I. 서 론}

미국의 가뭄과 폭염으로 촉발된 생산량 감소는 세계곡물 가격상승과 조사료 가격 상승으로 이어져 농가에 사료비 부담이 가중되고 있어 자급 양질 조사료 생산이 절실히 필 요한 실정이다. 그리고 우리나라는 산이 대부분을 차지하 기 때문에 일정규모의 초지조성 및 활용에 대한 필요성이 제기되고 있다. 우리나라의 초지면적은 산업화 및 도시화 로 매년 감소하여 2012년 약 4만 ha에 불과하다. 이들 초 지를 조성하는 대표적인 초종은 오차드그라스 (Dactylis glomerata L.)이다. 그러나 도입되는 오차드그라스 품종들 은 우리나라 기후에 적응성과 생산성이 떨어져서 초지 부 실화의 주요원인이 되고 있다. 일반적으로 오차드그라스는 다년생이며 북방형 목초로서 사료가치가 높고 재생력이 강 하며, 적절한 수분과 16 시간의 광조건하에서 생육 최적온 도가 $20 \sim 22^{\circ} \mathrm{C}$ 인 것으로 알려져 있고 (Eagles, 1967; Mitchell and Lucanus, 1962), 내한성이 일반적으로 강한 편이나
(Baker and Jung, 1968), 우리나라의 전형적인 여름 날씨인 무덥고 긴 장마에 약한 단점을 지니고 있다.

우리나라에서 목초 품종개발에 대한 연구는 1970년대에 시작하여 현재까지 개발된 오차드그라스 신품종은 1986년 최초로 합성 2호가 개발되었으며, 그 후에 2002년 장벌 101호, 장벌 102호, 2003년 코디(Kordi), 2005년 코디원 (Kordione)과 코디투 (Korditwo), 2011년 온누리 (Onnuri) 등 총 6품종이 육성되었다(Rim et al., 2003; Rim et al., 2004; Rim et al., 2004 ${ }^{\text {b; }}$ Ji et al., 2008).

목초 및 사료작물 품종개발에 대한 우리나라의 대상초종 은 오차드그라스, 이탈리안 라이그라스, 톨 페스큐, 잔디형 목초 등이 있으며, 이들의 육종목표를 살펴보면 내습, 내하 고, 내한성, 조숙성, 엔도파이트 프리, 내도복성 및 수량성, 사료가치, 내병충성, 영속성 등을 들 수 있다. 특히 우리나 라에서 오차드그라스는 무더운 여름철 고온과 긴 장마기간 을 견뎌야하기 때문에 하고와 습해에 강한 품종을 개발하 는데 그 목표를 두고 있다.

* Corresponding author: Hee Chung Ji, National Institute of Animal Science, Cheonan 330-801, Korea, Tel: +82-041-580-6749, Fax: +82-41-580-6779, E-mail: cornhc@korea.kr 
따라서 본 연구의 목적은 우리나라 기후에 적응성과 내 재해성 (내습성 및 내하고성 등)이 우수한 오차드그라스 신 규계통인 합성 28호를 2011년 직무육성 선정심의회에서 신 품종으로 선정된 오차드그라스 “온누리(Onnuri)”의 생육특 성, 사료가치 및 수량성에 대한 연구결과를 기술코자 한다.

\section{II. 육성경위}

\section{1. 우량계통 선발}

전국에서 수집된 생태형 중에서 1978년부터 1992년까지 내재해성 및 생육특성이 우수한 8계통을 선발하였다. 선 발된 영양개체를 증식한 후 계통 당 10 개체씩 계통화 하 였고, 생육특성을 조사하여 내습성 및 내하고성 등을 포 함한 생육특성이 우수하며 출수기가 비슷한 5 계통을 선발 하였다.

\section{2. 다교잡 교배}

1992년에 다교잡 설계(polycross design)로 합성포장을 조성하여 생육 특성이 우수한 5계통을 선발하여 이들 계통 에 대한 다교잡을 실시하여 합성계통을 육성하였다. 또한 화분의 유입을 차단하기 위하여 합성포장 주변에 호밀을 파종하였다.

\section{3. 생산력 및 지역적응성 검정}

온누리는 다른 육성계통들과 생산력 검정을 천안에서 2005년부터 2006년까지 2년 간 수행하였다. 그 후에 도입 품종인 암바 $(\mathrm{Amba})$ 를 대조로 하여 지역적응성 검정을 천 안, 평창, 진주 및 제주도를 포함한 4개 지역에서 2009년부 터 2011년까지 3년간 수행하였다. 파종일은 천안은 2008년 9월 17일, 평창은 2008년 9월 10일, 진주는 2008년 10 월 9 일 그리고 제주도가 2008년 10월 17일이었다. 파종량은 ha 당 $30 \mathrm{~kg}$, 파종면적은 $6 \mathrm{~m}^{2}$, 파종방법은 $20 \mathrm{~cm}$ 세조파로 하 였다. 시비량은 성분량으로 ha당 $\mathrm{N}-\mathrm{P}_{2} \mathrm{O}_{5}-\mathrm{K}_{2} \mathrm{O}=80-200-70$ $\mathrm{kg}$ 주었고, 이른봄 -1 차 4 차 수확 후에 질소와 칼리비 료는 ha당 $\mathrm{N}-\mathrm{P}_{2} \mathrm{O}_{5}-\mathrm{K}_{2} \mathrm{O}=210-150-180 \mathrm{~kg}$ 를 각각 $30-20-20-$ $10-20 \%$ 로 분시 하였으며, 인산비료는 이른 봄과 3 차 수확 후에 각각 $50 \%$ 씩 2회 분시 하였다. 시험구 배치는 난괴법 3 반복으로 실시하였다. 생육특성으로는 월동성, 출수기, 도 복, 병해, 초장, 풍엽성 및 재생력 등을 조사하였고, 수량조 사는 $6 \mathrm{~m}^{2}$ 시험구 전체를 수확하여 평량 하였다. 시료의
일반성분은 AOAC법 (1990)으로 분석하였으며, neutral detergent fiber (NDF)와 acid detergent fiber (ADF)는 Goering 과 Van Soest (1970)법으로 in vitro 건물 소화율 (in vitro digestibility, IVDMD)은 Tilley와 Terry (1963)의 방법을 Moore (1970)가 수정한 방법으로 분석하였다. 시험결과의 통계분석 방법은 SAS 프로그램 (SAS, 2004)을 이용하여 분 산분석을 실시하였고 처리 간의 비교는 Duncan 다중검정 법을 이용하였다.

\section{III. 결과 및 고찰}

\section{1. 생육특성}

오차드그라스 신품종 온누리의 생육특성은 Table 1 과 같 다. 온누리의 월동전과 봄의 초형은 중간형으로 암바 품종 과 같았으며, 출수기의 지엽 길이는 암바 보다 짧았고, 상 부 절간장 역시 암바 품종보다 짧은 편이었다. 풍엽성은 온누리나 암바 간에 비슷하였으며 초장은 온누리가 평균 $90 \mathrm{~cm}$ 로 암바 보다 $5 \mathrm{~cm}$ 길었다. 출수기는 온누리가 5월 16 일로 암바의 출수기인 5 월 21 일 보다 5 일 정도 빨랐다. 내재해성으로는 내습성이나 내병성은 온누리가 암바에 비 해 다소 강한 것으로 나타났다. 특히 녹병은 암바에 비해 약간 강한 편이었다.

Table 1. Agronomic and botanical characteristics of "Onnuri" (2009 2011, average of 3 years)

\begin{tabular}{lcc}
\hline \multicolumn{1}{c}{ Characteristics } & Amba & Onnuri \\
\hline \hline Growth habit & Medium & Medium \\
Flag leaf length & Long & Medium \\
Length of upper internode & Long & Long \\
Leafiness (1 9) & 1.0 & 1.1 \\
Plant height (cm) & 85 & 90 \\
Heading date (month.date) & May 21 & May 16 \\
Winter hardiness $(1 \sim 9)$ & 1.0 & 1.0 \\
Waterlogging $(1 \sim 9)$ & 1.6 & 1.1 \\
Regrowth $(1 \sim 9)$ & 2.0 & 1.8 \\
Disease resistance $(1 \sim 9)$ & 1.6 & 1.1 \\
\hline
\end{tabular}

* 1: strong or excellent, 9: weak or worst.

\section{2. 수량성}

오차드그라스 신품종 온누리의 지역적응성 시험결과 지 역별 건물수량은 Table 2와 같다. 2009 2011년, 3년 평균 
Table 2. Dry matter yield of "Onnuri" in regional yield trials

\begin{tabular}{|c|c|c|c|c|c|c|c|c|c|}
\hline \multirow{3}{*}{$\begin{array}{l}\text { Trial } \\
\text { region }\end{array}$} & \multicolumn{4}{|c|}{$\mathrm{Amba}(\mathrm{kg} / \mathrm{ha})$} & \multicolumn{4}{|c|}{ Onnuri(kg/ha) } & \multirow{3}{*}{$\begin{array}{l}\text { Average } \\
\text { Index }\end{array}$} \\
\hline & \multicolumn{3}{|c|}{ Year } & \multirow{2}{*}{ Average } & \multicolumn{3}{|c|}{ Year } & \multirow{2}{*}{ Average } & \\
\hline & 2009 & 2010 & 2011 & & 2009 & 2010 & 2011 & & \\
\hline Cheonan & 12,841 & 10,887 & 5,030 & 9,586 & 14,771 & 13,584 & 7,973 & 12,109 & 126 \\
\hline Pyeongchang & 13,533 & 11,286 & 12,538 & 12,452 & 12,960 & 14,273 & 13,157 & 13,463 & 108 \\
\hline Jinju & 15,030 & 16,280 & 9,960 & 10,440 & 13,690 & 16,230 & 12,670 & 14,197 & 136 \\
\hline Jeju & 22,151 & 16,858 & 13,828 & 17,612 & 21,731 & 17,746 & 18,512 & 19,330 & 110 \\
\hline Average & - & - & - & $12,523^{b}$ & - & - & - & $14,775^{\mathrm{a}}$ & 118 \\
\hline
\end{tabular}

${ }^{a, b}$ Means in the same column with different letter was a significant at the 0.01 level.

Table 3. Average nutritive value of "Onnuri" from 2009 to 2011 at cheonan (unit : \%)

\begin{tabular}{lccccc}
\hline Cultivar & Crude protein & IVDMD & TDN & NDF & ADF \\
\hline \hline Amba & 10.7 & 66.4 & 58.7 & 64.7 & 38.3 \\
Onnuri & 10.6 & 66.4 & 57.9 & 65.7 & 39.3 \\
\hline
\end{tabular}

IVDMD: In vitro Dry Matter Digestibility, TDN: Total Digestible Nutrient, NDF: Neutral Detergent Fiber, ADF: Acid Detergent Fiber.

온누리의 ha당 건물수량은 Table 2에서 보는 것과 같이 $14,775 \mathrm{~kg}$ 으로 암바 보다 $18 \%$ 의 증수를 보였고, 특히 진주 와 제주지역에서 수량 증가를 보였으며, 제주에서는 19,330 $\mathrm{kg} / \mathrm{ha}$ 로 최고수량을 나타내었다. 3년간의 수량성적을 근거 로 지역별 품종 간 수확량의 차이를 분석한 결과 지역 간 에는 $1 \%$ 의 고도의 유의한 차이를 보였으며 $\left(33.4^{* *}\right)$, 온누 리와 암바 간에는 $1 \%$ 의 고도의 유의한 차이가 있었다.

\section{3. 사료가치}

온누리의 사료가치는 Table 3에서와 같다. 분석결과 조 단백질은 암바와 거의 차이를 보이지 않았으며, In vitro 건 물 소화율은 $66.4 \%$ 로 암바와 같았다. 총가소화양분총량은 암바가 $58.7 \%$ 로 온누리에 비해 약간 높았다.

\section{IV. 요 약}

전국에서 1978년부터 1992년까지 수집된 생태형 오차드 그라스 계통들 중 생육특성 및 내재해성이 우수한 5 계통 을 집단 교배하여 생산된 합성종자를 2005년부터 2006년까 지 천안에서 생산력 검정시험이 수행되었고, 2009년부터 2011년까지 3년 동안 지역적응성 시험으로 천안, 평창, 진 주 및 제주지역에서 생육특성 및 수량성을 조사하였다. 2011년 직무육성 신품종 선정심의회에서 생육특성과 수량 성이 우수한 합성 28호를 신품종 “온누리”로 명명하였다.
온누리의 주요 특성을 요약하면 다음과 같다. 온누리의 월 동 전 및 봄의 초형은 중간형이며, 엽은 담녹색이고, 출수 기에 지엽 길이는 중간이며, 상부절간장이 길고 풍엽성이 양호하였다. 출수기는 5 월 16 일로 표준품종인 암바 보다 5 일이 빨랐으며, 출수기에 초장은 $90 \mathrm{~cm}$ 로서 암바 보다 5 $\mathrm{cm}$ 길었다. 내습성과 내병성은 온누리가 암바에 비하여 비 교적 강하였으며, 녹병은 온누리가 암바 보다 강한 편 이 었다. 온누리의 ha당 건물수량은 $14,775 \mathrm{~kg}$ 으로 암바 보다 $18 \%$ 많았고, 특히 제주지역에서 증수하였다. 온누리의 사 료가치는 암바와 비슷하였다. 이상의 결과를 요약하면 온 누리는 다수성인 중생종 계통으로, 특히 습해 및 내병성에 강하고, 건물 생산성이 많은 품종으로 초지 및 양질 조사 료 생산을 위한 우수한 품종이다.

\section{$\mathrm{V}$. 인 용 문 헌}

AOAC. 1990. Official methods of analysis (15th ed.) Association \& Official Analytical chemists, Washington DC.

Baker, B.S. and Jung, G.A. 1968. Effect of environmental conditions on the growth of four perennial grasses. I. Response to controlled temperature. Agronomy Journal. 60:155-158.

Eagles, C.F. 1967. The effect of temperature on vegetative growth in climatic races of Dactylis glomerata in controlled environments. Annuals of Botany. 31:31-39.

Goring, H.K. and Van Soest, P.J. 1970. Forage fiber analysis. Ag. Handbook. No. 379. ARS. USDA. Washington, D.C. 
Ji, H.C., Choi, G.J., Sung, B.R., Seo, S., Kim, K.Y., Lee, J.K., Kim, W.H., Park, H.S. and Moon, C.S. 2008. Growth characteristics and productivity of new orchardgrass variety "Korditwo". Journal of the Korean Society of Grassland and Forage Science. 28:1-6.

Mitchell, K.J. and Lucanus, R. 1962. Growth of pasture species in controlled environment. III. Growth at various levels of constant temperature with 8 and 16 hours of uniform light per day. New Zealand Journal of Agricultural Research. 5:135-144.

Rim, Y.W., Choi, G.J., Sung, B.R., Lim, Y.C., Kim, M.J., Park, G.J., Kim, K.Y., Chung, J.W. and Park, N.G. 2003. Growth characteristics and productivity of new orchardgrass variety "Jangbeol 101". Journal of the Korean Society of Grassland and Forage Science. 23:203-206.

Rim, Y.W., Choi, G.J., Sung, B.R., Lim, Y.C., Kim, M.J., Park, G.J.,
Kim, K.Y., Chung, J.W. and Go, S.B. 2004 $4^{\mathrm{a}}$ Growth characteristics and productivity of new orchardgrass variety "Kordi". Journal of the Korean Society of Grassland and Forage Science. 24:261-264.

Rim, Y.W., Choi, G.J., Sung, B.R., Lim, Y.C., Kim, M.J., Park, G.J., Kim, K.Y., Chung, J.W. and Go, S.B. 2004 $4^{\mathrm{b}}$ Growth characteristics and productivity of new orchardgrass variety "Jangbeol 102". Journal of the Korean Society of Grassland and Forage Science. 23:207-210.

SAS. 2004. SAS/STAT 9.1 User's Guide. SAS inst, In, Cary, NC.

Tilley, J.A.M. and Terry, R.A. 1963. A two stage technique for in vitro digestibililty of forage crops. Journal of Birtannica Grassland Science. 18:104-111.

(Received November 30, 2012/Accepted February 5, 2013) 